\section{Epidemiologists working together with anthropologists: lessons from a study to evaluate the epidemiological impact of a city-wide sanitation program}

\author{
Epidemiologistas e antropólogos trabalhando \\ juntos: lições de um estudo para avaliar o impacto \\ epidemiológico de um programa de saneamento \\ urbano
}

\section{Los epidemiólogos y antropólogos que trabajan juntos: lecciones de un estudio para evaluar el impacto epidemiológico de un programa de saneamiento urbano}

\begin{abstract}
This paper discusses the role of qualitative approaches in epidemiological studies, beginning with a general discussion of epidemiological and anthropological methods. It focuses on a case study of the health impact of an environmental intervention carried out in Salvador, Bahia State, Brazil. Most of the precedent studies fields, based on primary date, use to devote little attention to the methodological and theorethical questions at tached to long-term studies. Four specific aspects of this experience are highlighted: (a) drawing up epidemiological study; (b) construction of an observational instrument to measure hygiene habits; (c) an ethnographic study that was carried out before the epidemiological study; (d) observation of the effects of health intervention on health inequalities. Finally, the report details how the findings of qualitative and quantitative studies might be synthesized. It provides a critical overview of follow-up strategies, illustrated with proper examples whenever possible.
\end{abstract}

Medical Anthropology; Sanitation; Impacts on Health
Cristina Larrea-Killinger 1,2

Rita Franco Rego 3

Agostino Strina 4

Mauricio L. Barreto 4

\section{Resumo}

Este artigo discute o papel das abordagens qualitativas em estudos epidemiológicos, começando com uma discussão geral de ambos os métodos. Centra-se em um estudo de caso sobre o impacto na saúde de uma intervenção ambiental em Salvador, Bahia, Brasil. A maioria de estudos nesta linha, que derivam de pesquisas de fonte primária, traz pouca discussão sobre as questões metodológicas e teóricas envolvidas em estudos em longo prazo. Quatro aspectos específicos dessa experiência são especialmente destacados: (a) elaboração de questionários para o estudo epidemiológico; (b) construção de um instrumento observacional para medir os hábitos de higiene; (c) um estudo etnográfico que antecedeu a pesquisa epidemiológica; (d) observação dos efeitos da intervenção de saúde sobre as desigualdades de saúde. Finalmente, o estudo considera em detalhe como os resultados dos estudos qualitativos e quantitativos podem ser sintetizados. Ele fornece uma visão geral e crítica das estratégias de acompanhamento, ilustrada, sempre que possível, com exemplos apropriados.

Antropologia Médica; Saneamento; Impactos na Saúde 


\section{Introduction}

A brief look at the history of social medicine suggests that, at least in principle, epidemiology and anthropology are natural allies in studying diseases in human populations. Despite its conceptual and methodological evolution over recent decades, however, modern epidemiology has been subject, mainly from social sciences, to a variety of criticisms, especially in relation to its capacity to make significant contributions towards understanding and solving the complex health problems of populations. As a possible solution to this theoretical and methodological inertia, some authors have proposed to advance on an interdisciplinary type of approach, through greater empirical proximity between epidemiologists and anthropologists 1,2.

The search for a wider-ranging comprehension involving elements of high complexity within the health-disease process has not been completely forgotten as an aspiration in epidemiology. Some authors $1,2,3,4$ have indicated studies with interdisciplinary or transdisciplinary approaches, or adopting multiple methods (triangulation), as a means of empirical approximation to comprehend complex questions.

Twenty-first century epidemiology would benefit from concentrating on integration of concepts and methods from other disciplines into the field social and human sciences, such as anthropology, in order to comprehend new complexities by placing the center of analysis on the subject's experience and the sociocultural context within which this experience is produced. Interdisciplinarity arises from recognition of the limitations that a single field of knowledge has with regard to solving wide-ranging and complex problems 3.

\section{Collaboration between epidemiology and anthropology}

Studies of health-disease-care processes produced through integration of epidemiology and anthropology started to become a reality more than two decades ago. A body of literature $5,6,7,8,9,10$ has indicated contributions and limits of this integration in theoretical and methodological development. In fact, interdisciplinary collaboration, which was more apparent than real in the past, started to become more effective in the twentieth century, especially during the 1980s 11 .

Medical anthropology provides a comprehensive approach to interpreting the human processes of falling ill by taking into account the combination of subjective interpretations of individuals who get ill and collective representations of these processes. Despite the fact that medical anthropology seldom establishes generalized rules apt to explain human behavior in relation to the health-disease-care process, it allows more careful interpretations of this behavior within specific sociocultural contexts, as well as intercultural comparisons.

The qualitative approach to the reality of the sociocultural contexts in which subjects live is what leads anthropology to be sought by epidemiologists, but, at the same time, to be turned down, because of the lack of so-called "scientific rigor" as far as the theoretical and conceptual bases of epidemiology.

Anthropologists and epidemiologists have different ways to study the social and cultural context in their investigations. Anthropological fieldwork relies on the principle of reflexivity 12 , which is often discarded when epidemiological data are collected, on the assumption that epidemiologists should adopt a neutral role throughout the investigative process. According to anthropologists, epidemiologists are more distant from the events investigated, and transform the participants' lives into a mere set of numerical variables, without any relationship with their social and cultural context ?

Anthropologists usually carry out their investigations separately from other researchers and closer to the participants. This leads them, on the one hand, to a greater commitment to the research subjects, and on the other hand, to a greater care in discussing, analyzing, and presenting data. Traditional anthropology requires spending a significant amount of time in the field, usually living together a population for years, and individual authorship is more likely a result of scientists studying a population by themselves, rather than unwillingness to share findings. In the epidemiological approach the relationship between the subjects and their social context is captured as quantitative variables that must be collected in the same manner by all interviewers. Consequently, teamwork strategies are developed within epidemiology, and these facilitate the discussion and interchange of information published in scientific articles with multiple authorship. These differences in the investigative modus operandi between these two fields of knowledge become more evident during interdisciplinary practice. Despite of conceptual and methodological, and offered, in order to some authors have demonstrated profitable experiences of collaboration between these two disciplines 1 .

Especially to study the impact of health interventions on behavioral changes. Several theoretical models have been proposed in health studies, 
traditionally more concerned with how social cognitive models affect individual rather than community changes. For this reason, the aim of using a more collaborative approach to understand public health interventions is to explore critically the dimensions of culture 13 .

It should be emphasized that in both these disciplines, theoretical and methodological efforts have been made towards expanding collaboration, even if these have so far been insufficient, fragmented, and incomplete 9,14,15. On the one hand, some epidemiologists have highlighted the benefits derived from using qualitative methods, particularly in the early phases of an investigation; on the other hand, anthropologists have emphasized the differences rather than the similarities between these disciplines. There are epidemiologists reluctant to such collaboration on the grounds that anthropologists are too descriptive and subjective, thus unscientific, given that they study too few cases and disregard the principles of statistical inferences. On the other hand, anthropologists complain that epidemiologists are generalists, tending to homogenize and make very little use of conceptual origins as a basis, for example the concept of culture 1 .

In the debate between epidemiologists and anthropologists, concern about getting over the differences between the disciplines is frequently expressed. Authors such as Dunn \& Craig ${ }^{5}$ have observed that these theoretical-methodological differences stimulate the complementary relationship between the disciplines, while Bibeau 16 and Menéndez 7 focused on their integration.

Bibeau 16 highlighted two fundamental differences between the disciplines: (1) epidemiology is centered exclusively on studying disease, instead of first focusing on the analysis of the social problems and the biomedical origin of disease definition; and (2) anthropology takes into account the sociocultural dimension of becoming ill and the interpretation of the symptoms reported by the subjects. The epidemiologist Almeida Filho 17 also came to the same conclusion by observing that epidemiology did not pay attention to the subject's experience and the sociocultural context within which this experience occurred. It is not just a matter of constructing analysis models in which sociocultural variables are included, but rather to recognize that the social context is part of an ethno-epidemiological whole.

Menéndez 7 also reflected on the difficulties that beset the collaboration between the two disciplines, are emphasized the epistemological differences in constructing analysis categories. Epidemiology does not take the sociocultural and historical origin of the analysis categories into consideration, thus limiting comparisons and interpretations of the processes of becoming ill.

Menéndez ${ }^{7}$ highlighted epidemiological reductionism and Almeida Filho 17 considered that lack of theoretical validation for concepts that epidemiology borrows from other disciplines favors uncritical and instrumental incorporation of these concepts, thereby reducing them to simple numerical variables. According to Almeida Filho 17, this becomes evident in studying the independent variables that make up the theoretical models of epidemiological surveys, which are not properly elaborated and are not discussed in depth.

The relationship that medical anthropology has with the biomedical model has always been delicate, in that it questions medical power, the process of medicalization of healthcare knowledge and practices, the ethnocentrism inherent to the modus operandi of the biomedical model, and the tendency to homogenize the knowledge and practices of public health within the international sphere. Medical anthropologists taking a critical view 18,19 have already argued about the excessive use of medical terms and the rendering of ethnographic data as quantitative variables in collaborative investigations between anthropology and medicine. For example, within this context of methodological adaptation of anthropology, a variety of research strategies have been developed, such as the well-known rapid ethnographic method 20 .

Authors such as Frankenberg 19, Bibeau 16, Hersch \& Haro 21, and Menéndez 7 recognized that the main limitation of anthropology the excessive culturalism as applied to the health field, and offered, in order to overcome this limitation, they propose the theoretical strategy of allowing structural factors to take on greater relevance in analyzing the health-disease-care process. Economic, political, and social factors should be taken into account in order to better explain the process of disease and patient construction.

The scientific literature centered on efforts to specifically produce specifically and interplay between epidemiology and medical anthropology can be classified into three concrete theoretical-methodological proposals, namely, ethno-epidemiology 17,22,23, sociocultural epidemiology 7,21, and cultural epidemiology 11,24. Although other theoretical models of interdisciplinary synthesis (like the social ecology model of Panter-Brick et al. 13) are not analyzed in this article, in Latin America (Mexico and Brazil) these theoretical and methodological proposals have been used to solve practical investigation issues and to find more integrated solutions 
for the future of interventions. In collaboration efforts, it is not intended that the potential inherent to each field of knowledge should be lost. In analyzing the specific features of each discipline and observing how they engage with each other in an interdisciplinary manner, one sought to construct a more effective space for dialogue that makes possible the elaboration of a new field of knowledge that is more holistic, wide-ranging, and respectful with regard to the differences specific to each discipline.

For anthropologists and epidemiologists to achieve a more human synthesis at social and cultural levels, a process of demedicalization of healthcare knowledge and practices is needed, with incorporation of a more holistic and diverse view of social subjects and integration of tools providing greater depth, such as ethnography and the incorporation of qualitative techniques into investigations.

The aim of this paper is to describe and advance a constructive critique, both theoretical, and methodological, starting from a collaboration between epidemiologists and anthropologists within the context of a large study that sought to evaluate the health impacts of an environmental sanitation program (the Bahia Azul Program) in Salvador, Bahia State, Brazil, for which the main outcomes assessed were childhood diarrhea 25 and intestinal parasite infection 26,27.

Four specific aspects of this experience are highlighted: (1) elaboration of epidemiological questionnaires; (2) construction of an observation tool that allowed the epidemiologists to measure hygiene habits and thus include them in their quantitative analyses; (3) an ethnographic study on rubbish and diarrhea, that preceded the epidemiological investigation and served to place the epidemiological investigation in context; and (4) observation of the effects of the sanitary intervention on health inequalities, from the macro to the micro level. Based on an analysis of these four concrete experiences and the different degrees of intersection between them, the authors (epidemiologists and anthropologists) discuss the possible implications and contributions of this experience towards fostering interdisciplinary dialogue between epidemiology and anthropology (Figure 1).

\section{Epidemiological approach}

As part of the study to evaluate the Bahia Azul Program, three longitudinal studies (1997, 2001, and 2004) were carried out in Salvador, the capital of Bahia State, located in the Northeastern region of Brazil. The city has a population of approximately 2.5 million inhabitants.
The study setting, for which details have been given elsewhere 25,26,27,28,29, consisted of 30 "sentinel areas", i.e., aggregates of census tracts randomly selected in different districts of the city. Three of them were located in a high living standard district, with a long-established sewage system, thus serving as the benchmark for the environmental and health factors to be monitored; three were located in a district with intermediate living conditions, in which the sewage system had been recently been established; and the remaining 24 were located in eight districts that were among the poorest in the city and lacked sewage systems at the time of this study but would get them during the execution of the Program (Table 1).

\section{Anthropological approach}

To evaluate the social experience of becoming ill and healthcare strategies relating to sanitation conditions, two districts , Nova Constituinte and Baixa da Soronha, were selected for comparison, with the intention of observing the sociocultural differences and similarities that individuals developed in distinct periurban spaces, with emphasis on studying representations and practices regarding diarrheal diseases and the evolution of sanitation conditions.

The population data used in this survey was obtained by adding up the populations living in the census tracts corresponding to these districts. The 1996 population count database and the 2000 census database were obtained from the Brazilian Institute for Geography and Statistics (IBGE; http://www.ibge.gov.br).

In 1997, Nova Constituinte population consisted of 9,748 inhabitants, with a mean monthly income of 1.39 minimum wages and a mean schooling level that did not go beyond the first four years of primary school. In 1998, construction of the sewage system began in half of the district and households started to be hooked up to the system in 2003. In this same year, Salvador city authorities began distributing title deeds granting home ownership and implemented the Family Health Program at a new health clinic. By 2007 , only $60 \%$ of the families were connected to the sewage system, and the district population had grown to a total of 18,077 inhabitants. Although the urban infrastructure improved, poor maintenance of the system resulted in a deficient and irregular sewage system. In the Baixa do Soronha district in 1996, there were 2,671 inhabitants earning a mean of 2.44 minimum wages per month. Construction of the sewage network in this locality began in 2003. 


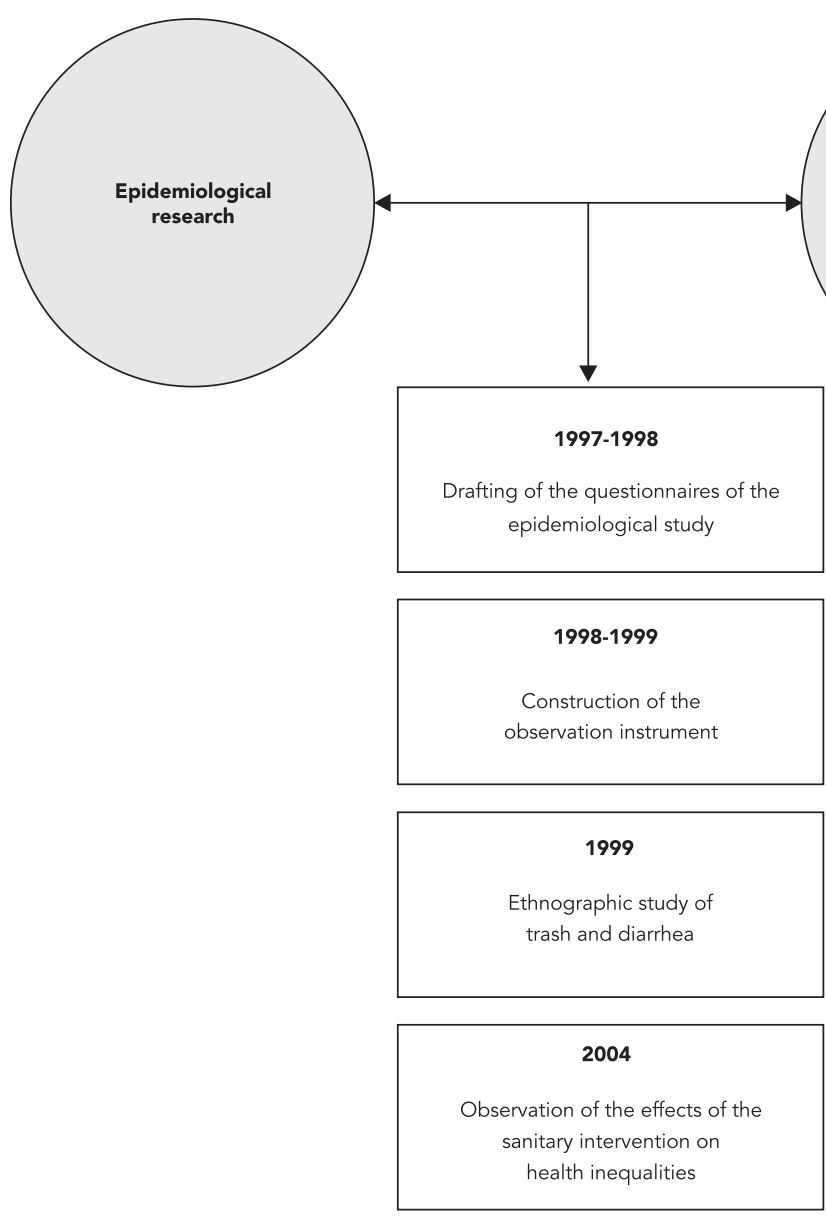

This ethnographic research lasted from 1997 to 2008, in different stages, and was based on participative observation of day-to-day social and cultural dynamics of 62 households (Table 1). The ethnographic techniques included indepth interviews on the health-disease-care process, acquisition of life histories and genealogical data, observations on health and sanitation, production of district maps and house plans, filming, photography, and community activities before and after installation of the sewage system.

\section{Working together}

\section{Drafting of the epidemiological questionnaires}

The interdisciplinary collaboration began by drawing up a socioeconomic questionnaire and a questionnaire for mothers with children aged 0 to 3 years, which were applied at all three stages of the epidemiological study. Ethnography made it possible to incorporate popular terms and categories that were usual within the local context. For example, a term equivalent to fatigue (canseira) was used to refer to "rapid and difficult respiration". In the instrument for home follow-up applied to children, the category of "tiredness" was incorporated as a disease. 
Table 1

Comparison of epidemiological and anthropological fieldwork stages.

\section{Epidemiological fieldwork}

Fieldwork

Approximately 20,000 households located in selected areas of the city were surveyed, and those with children under three years of age were picked at random from the full list. Only one child within the eligible age range ( 0 to 36 months) was enrolled in each household

At the time of recruitment for the study, a precoded questionnaire was applied to mothers or other relatives caring for children most of the time (father, aunts, grandmothers, or sisters), aimed to gather data on a number of socioeconomic and environmental

factors (both peridomestic and domestic) related to the household 25

The team included an epidemiologist, a graduate field coordinator, and 15 fieldworkers who had all completed secondary education

The children were followed up with biweekly home visits at an interval of 72 to 96 hours. During the visit the fieldworker questioned the mother/other caregiver, with reference to the preceding 3-4 days, about the occurrence of diarrhea, and also recorded, for each day, number and consistency of bowel motions, occurrence of additional symptoms (such as vomiting, fever and blood in stools), and management strategies implemented by the mother/caretaker (such as rehydration, use of medicines, and resorting to medical care)

A day with diarrhea was defined as the occurrence of three or more loose or liquid motions over a 24-hour period, starting when the child woke up in the morning 47 , and the proportion of days with diarrhea (the "longitudinal" prevalence) was used as a measure of morbidity. The association of diarrhea with a given factor, such as hygienic behavior, was expressed as a prevalence ratio and estimated through Poisson regression analysis

Informed consent was required for all participants at all the stages of this study in conformity with what is established in the 196/96 Resolution on research involving human subjects

\section{Anthropological fieldwork}

Priority to ethnography was given in observing practices and representations of disease, health, hygiene, and sanitation, before and after the sewage system was constructed in both districts studied

In the district of Nova Constituinte, the field survey lasted for 44 months. There were two intensive stages (1997-1999 and 2003-2004) and other shorter stages between 2000-2003, and 2005-2008

In the district of Baixa da Soronha, the duration of the field survey was slightly shorter, with a total of 26 months between the first stage and the second one

In the district of Nova Constituinte, the ethnographical fieldwork during both principal stages was conducted by two female anthropologists, supervised by the study coordinator. The coordinator worked in the field in both main stages, and in the remaining shorter ones

In the district of Baixa da Soronha, the ethnographical team was formed by two female anthropologists in the first stage and a single female anthropologist in the second stage, supervised by the study coordinator

The ethnographic results were presented in the two districts by means of several workshops in the presence of community leaders and community health agents

Between 2007 and 2010, a documentary video was produced showing the main results from the survey in the Nova Constituinte district

All participants were informed of the objectives of the study. Their anonymity was guaranteed at all times

(continues) 
Fieldwork

stages
A cohort of 1,153 children was followed up in the first study, which took place from December 1997 to April 1999. The second cohort, comprising 1,233 children, was carried out from October 2000 to January 2002. The third study lasted from October 2003 to May 2004 and followed up 1,127 children

The first study was carried out in 30 areas of the city; the second and third study only included children from the 24 poorest areas out of the total of 30

\section{Nova Constituinte}

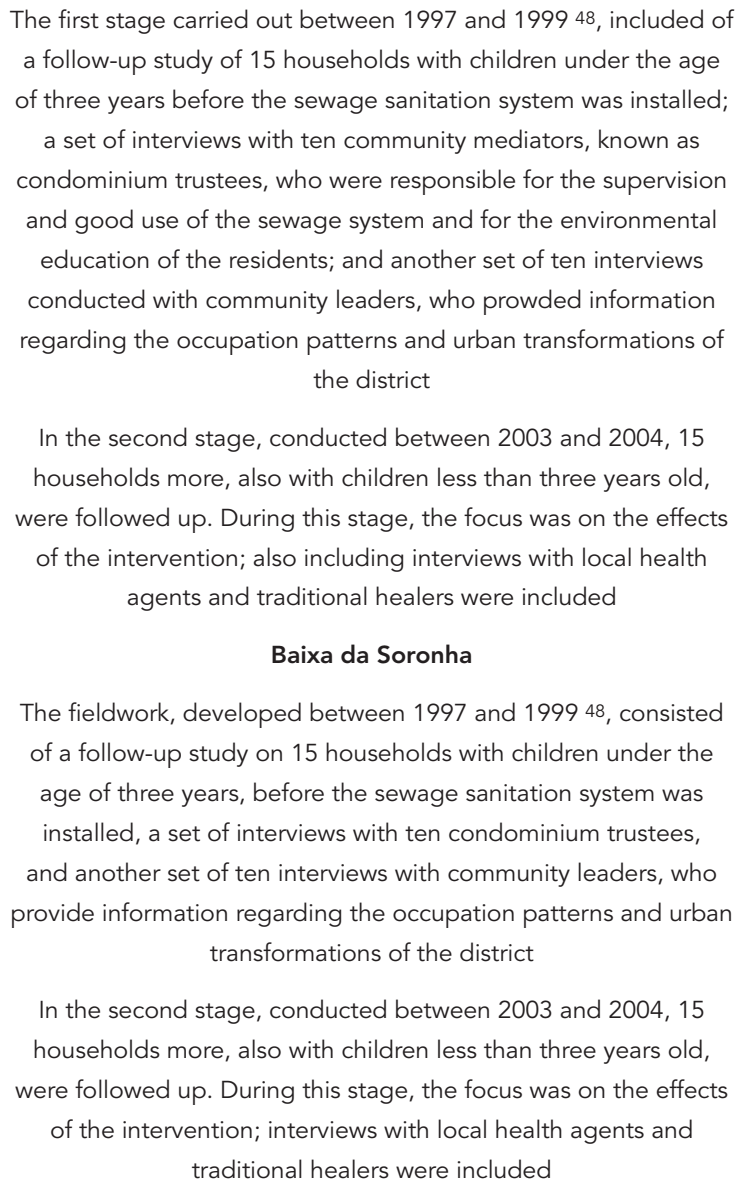

The first stage carried out between 1997 and 1999 48, included of ollow-up study of 15 households with children under the age three years before the sewage sanitation system was installed; a set of interviews with ten community mediators, known as and good use of the sewage system and for the environmental education of the residents; and another set of ten interviews conducted with community leaders, who prowded information the distric

In the second stage, conducted between 2003 and 2004, 15 were followed up. During this stage, the focus was on the effects agents and traditional healers were included

Baixa da Soronha

The fieldwork, developed between 1997 and 1999 48, consisted of a follow-up study on 15 households with children under the system was and another set of ten interviews with community leaders, who transformations of the district

The anthropological investigation allowed important decisions to be taken that influenced the validity of the study, for example with regard to who would be the most suitable interviewees. It was observed that many families were matrifocal (headed by women without husbands or male partners) and that the children were not only cared for by biological mothers, but also by other women. Questions relating to the other relatives were therefore introduced. The degree of kinship between the person responsible for a child (natural mother, adoptive mother, stepmother, grandmother, etc.) and the person responsible for caring for the child was investigated. Given that there are differences between the definition of the biological parent (genitor) or the person legally responsible for the child and other caretakers (who spend the greatest time caring for the child), it was asked who was spending the most time caring for the child included in the study. Considering these definitions, it was decided that these other relatives would be the preferred interviewees, since they would have more trustworthy information and would be able to answer most of the questions regarding the child's customs and habits. Since the participants were women, it was also decided to select female interviewers, which would made easier the access to the households.

Ethnographic insights gave rise to changes in the epidemiological questionnaire. From it, situations in which several families cohabited within the same household could be recognized. In such 
cases, for the epidemiological study, it was necessary to decide who would be interviewed as the mother of the child in the family. Since the questionnaire focused on an individual (i.e. a an under 3 years old child), it was also possible for the person responsible to be part of a more extended kinship unit. Since the diversity of kinship organization was too complex to be dealt with in the questionnaire, an instrument that attempted to respect this reality as much as possible was designed.

As the primary unit of analysis in the epidemiological study was the individual and the family was the first level of social organization, there were some difficulties in gathering information. Childcare is usually shared by several members of the family, and this needed to be captured by the epidemiological instrument. Moreover, homogenization of the "family" category as a "nuclear family" formed by the biological mother and father and several children did not correspond to the social reality encountered. There were a diversity of family models (extended, single-parent, or reconstituted), that the questionnaire partially took into account by integrating degrees of kinship with the child and support for the family. These limitations of the epidemiological instrument were better clarified and complemented by the anthropological study.

\section{Construction of an observation instrument}

A specific approach was adopted for investigating hygiene behavior. Hygiene behavior has been studied mainly through questionnaires or by direct observation 30,31,32. However, the consistency between reported and observed behavior has been found to be low 33,34. Behavioral patterns that are deemed to be appropriate (such as hand washing before handling food for the family or before eating) are precisely those that tend to be reported more frequently than they are observed 35. Besides that, structured observation may be biased through reactivity, i.e. people who are under observation may modify their behavior according to what they think the observer expects 35 . To bypass this difficulty, it was decided to adopt the less intrusive spot-check observational method 36. Spot-check observations had to be performed very discreetly, and interviewers recorded their observations on the form only after leaving the house. Finally, we needed to get individual measurements of behaviors that were as stable as possible at different times. A study conducted in Burkina Faso showed that in most behavioral patterns investigated, the degree of repetition of a given type of behavior by the same individual at different times did not go beyond moderate, with a concordance rate of less than 0.60 37. Capitalizing on the longitudinal design of this study, we performed repeated observations over a long period, during the biweekly home visits (Table 2).

\section{Ethnographic study on trash and diarrhea}

The scarcity of published studies correlating trash and diarrhea, the definition of trash that was closer to the context of this study, and the great emphasis that the population observed and interviewed by the anthropologist placed on trash as a public health problem led to our study being focused on the association between trash and diarrhea. It was sought in this investigation to achieve a better understanding of the significance of trash: how people define trash and what the relationships are between trash and disease and between trash and other environmental factors. This study aimed to guide the compilation of questions for the epidemiological questionnaire, but the results from this study also added important elements towards the construction of the conceptual model and interpretation of the results of the epidemiological study 38 (Table 3).

The ethnographic insight also contributed towards introducing the concept of the "peridomestic area" as a definition for the space presenting risk to health. From observations on children's movements and around the outside of the home, in the backyard, and in the street, and the presence of trash and feces in these areas, these spaces were characterized as "peridomestic areas" and were revealed to be important as spaces with an environmental risk of occurrences of diarrhea. Since peridomestic spaces are at the boundary between the public and private domains, it becomes very easy for the public sanitation authorities not to hold themselves responsible for them. Such areas are also an easy target for neighborhood conflicts, given that there are no clearly defined property limits. The existence of peridomestic areas also implies that transmission of infectious diseases occurs within both the public domain and the domestic domain, and that control is required in both domains. The distinction between the transmission of infectious diseases within the domestic domain (the area normally occupied by and under the control of a household) and within the public domain (including public places of work, schooling, commerce, and recreation, along with streets and fields) was studied by Cairncross et al. 39 . Whereas transmission in the public domain may allow a single case to cause a large epidemic, transmission in the domestic domain is less dramatic and often ignored, even though it may account for a 
Observational instrument

Behaviors patters

Results
The epidemiological method was of interest because it gave rise to an observational instrument that translated the ethnographic observations on hygiene behavior into variables that could be subjected to quantitative analysis. Among the set of observations made by the anthropological team, the epidemiologists highlighted those that were centered on behavior relating to the epidemiological risk model: for example, putting a pacifier into the child's mouth without washing it first, or throwing out the dirty water from washing the diapers in the backyard, etc.

Based on the experience and knowledge of the population's habits and daily practices acquired by the anthropological team, twenty-four specific behaviors were selected. It was felt that these were likely to occur (and, thus, to be registered during the fieldworker's short stay in the household) and also to be relatively stable, while concomitantly strongly associated with diarrheal disease within the epidemiological experience. These behaviors patterns (termed "positive" or "negative", in the epidemiological meaning of respectively preventing or favoring the transmission of diarrhea) were related to the child being investigated and to its mother or caregiver

The prevalence of diarrhea among children for whom "mainly unhygienic" behaviors was recorded was 2.2 times (95\% confidence interval: $1.7,2.8)$ greater than among children in the "mainly hygienic" group. The relative risk fell to 1.9 (95\% confidence interval: $1.5,2.5)$ after the data were controlled for confounding factors, but the difference was still highly significant. This study has been described in greater detail elsewhere 49 substantial number of cases 40 . To control transmission in the public domain, intervention by public authorities is likely to be required. However, to interrupt disease transmission, interventions are required in both domains.

\section{Observation of the effects of sanitary intervention on health inequalities}

This interdisciplinary work went beyond the methodological process. Different attempts to produce a synthesis over the course of the survey were taken into account in order to reach a more epistemological reflection that would bring contributions to epidemiological and anthropological knowledge, thereby breaking down the dichotomy between quantitative and qualitative approaches. Concepts of context and social inequalities were defined starting from both epidemiology and anthropology, in order to observe how these concepts operated at the methodological level in the evaluation study. In the epidemiological study, it was observed that the occurrences of diarrhea and intestinal parasites 26,27 tended to converge between the areas with and without sanitation and, therefore, sanitation had a positive effect on reducing health macro-inequalities. Nonetheless, despite the expansion of the sewage system in the city, social inequalities continued, thereby explaining differences in health within the urban area ${ }^{41}$.
From the anthropological observations, it was concluded that in at least one of the areas, social inequalities worsened. This was because the benefits from installation of the sewage system were unequal. In one part of the area benefited, not all of the homes were hooked up to the system, while another part of the area was not benefited. This generated internal inequalities (with or without sanitation), whereas no such inequality had previously existed because nobody had access to a sewage system 41 . Thus, the benefit from sanitation had a large impact on diseases (diarrhea and intestinal parasites) of major importance at the macro-quantitative level, but the advent of sanitation meant that new forms of inequality appeared at the microqualitative level.

\section{Discussion}

This collaborative scenario between anthropology and epidemiology, within the context of a large study that sought to evaluate an environmental sanitation program using the health variables of childhood diarrhea 25 and infection by intestinal parasites among preschool children 25 and schoolchildren 26 , produced a variety of lessons of an epistemological nature, along with conceptual and methodological advances. Four specific examples from this experience are highlighted in 
Trash and diarrhea interviews: how epidemiological methodology was applied semi-structured interviews in an ethnographical context to construct a theoretical model of analysis.

\section{Trash and diarrhea interviews}

Fieldwork

Results
The interviews were conducted in October 1999, by an epidemiologist and an anthropologist during the course of the abovementioned ethnographic study in Nova Constituinte.
The preceding ethnographic study made it easier to apply the 13 semi-structured interviews with community leaders and heads of households. The following items were investigated: what trash is, in the subject's view; why trash is a problem; trash and diseases; trash and other environmental factors; and individual and collective responsibility regarding trash. The results from this study have been published in detail elsewhere 38.

The results allowed the epidemiologists to construct a theoretical model to explain the results of the epidemiological study. In the study by Rego et al. 29, children who had a dumping ground near their homes had $32 \%$ more days of diarrhea than did those living in places without any dumping ground in the vicinity. In fact, a trash dumping ground nearby allows vectors such as flies to proliferate. This proximity to trash grounds therefore exposes children to both direct and indirect contact with diarrheal agents.

These authors showed that the presence of a trash dump near the home (maximum distance of 100m) (prevalence ratio $-\mathrm{PR}=1.32 ; 95 \% \mathrm{Cl}: 1.05-1.65)$ and negative habits regarding dumping of trash in peridomestic areas (presence of food leftovers, stools, and accumulated unbagged trash dumped in the front area or in the backyard of the house, or a child playing on the trash dump) ( $P R=1.32 ; 95 \% \mathrm{Cl}: 1.07-1.64)$ were significant factors for the incidence of diarrhea.

These results, together with evidence from the urban sanitation service that $5 \%$ of the domestic trash was contaminated with feces, were explained based on the conclusions from the anthropological study, which had pointed out that feces from members of the family that were put out with the trash and feces from the children that were poorly wrapped and thrown into peridomestic areas were in fact contributing significantly towards occurrences of diarrhea among children under the age of three years.

Trash is a dynamic category that is limited by its exchange value. It was defined by the interviewees in terms of its usefulness, final disposal, and relationship with health (i.e. whether it caused diseases). The definition most used was that "trash is everything that does not serve for any use", i.e. things that cannot be formed into products for use, sale, or exchange. Some products classified as trash were also considered to be reusable or recyclable. Things that were considered to be "old", but that had some use, were not classified as trash. According to interviewees, things that were trash in some people's view could be considered to be of great use by others. On the other hand, the products that were unanimously listed as trash, without any possibility of reuse or recycling, included the following: dirt gathered through sweeping, scrub vegetation, human and animal feces, used toilet paper, and spent radio batteries.

Human and animal feces and used toilet paper were considered to be trash, partly because of the lack of sanitation in the homes. This led families to wrap feces in newspaper and plastic bags and deposit them in streams, channels that served as sewers, ditches, or domestic trash points. Feces were generally buried in the backyard of the house or close to it in bags that were kept separate from the daily trash production. This method of feces disposal promoted contamination of the peridomestic space. The final disposal was in the same place as used for the domestic trash. The feces of young children were frequently thrown out into the backyard, usually without wrapping, even though this was also a place where children would play. Younger children's feces were not considered by their parents to be harmful to the health of children playing in the peridomestic area this paper. From analysis of these experiences, the possible implications and contributions towards advancing the interdisciplinary dialogue between epidemiology and anthropology are discussed.

The great challenge in drafting the epidemiological questionnaire consisted of integrating concepts from the different disciplines that formed part of the interdisciplinary project. The different theoretical and methodological dimensions needed to be joined together in order to design an instrument that was better adapted to the studies objective. In this respect, epidemiology had an important role as a mediator of knowledge from the biological and social sciences. However, certain disciplinary limitations between epidemiology and anthropology can be highlighted 42 , with regard to reduction of so- 
ciocultural dimensions (family, gender, hygiene, etc.) to quantifiable variables and the "epidemiologization" of analysis units that have a strong sociological tradition, as homogenous concepts (for example, culture, religion, gender, etc.). These issues created difficulties in the initial dialogue for drafting the data gathering instrument, and the team decided to conduct a pilot study to verify the categories that were causing conflict at the team level.

The questionnaire attempted to respect local realities as much as possible and to integrate certain popular categories. Efforts had to be made in this respect, for example by incorporating greater ethnographic sensitivity into the epidemiological survey, which influenced the selection and training of interviewers, along with epidemiologists' participation in community activities.

Construction of an instrument for observing hygiene habits required collaboration between epidemiology and anthropology. This facilitated greater understanding among epidemiologists of the role that social perceptions develop based on knowledge of risk and the corresponding behavior. It is widely acknowledged that although adequate excreta disposal and water supply are strongly associated with reduction of diarrhea among children, achievement of the full impact from these interventions depends on behavioral changes relating to domestic hygiene 43 . Anthropological insight is important from another standpoint that is of great concern in the field of health impact evaluation studies. The lack of evidence of reduced incidence of diarrhea that has emerged in some studies, in spite of modifications to hygiene behavior, could in fact be dependent on the fact that "...because these studies relied upon interventions formulated according to a priori reasoning, (the results) may have reflected inadequate attention to local practices that were determinants of childhood diarrhoea in the communities under study" 30 (p. 289). Such factors could have been identified, had an anthropological approach been applied.

The anthropological study that preceded the epidemiological study on trash and diarrhea emerged from the comprehension that the phenomena of health and illness constitutes a complex social process that require a combination of different research strategies in seeking to explain the reality. In studying the relationship between trash and diarrhea among children, the greater generalizing potential of the quantitative method was used in the first stage of the investigation. In this case, the quantitative method came from an epidemiological study, and greater depth was then achieved through the qualitative method, in seeking better quality of investigation. Hammer- sley 44 identified three approaches for research that uses multiple strategies: triangulation, when one method is used to verify the findings of another; facilitation, when one strategy facilitates or helps another; complementariness, when two strategies are used to investigate different aspects of the problem. In the present investigation, all these elements were used, thereby seeking to achieve an integrative approach between qualitative and quantitative evidence, improve the accuracy and relevance of quantitative evidence, identify appropriate variables to be measured, explain unexpected results, and generate hypotheses to be tested through quantitative research. This integrative approach between qualitative and quantitative evidence has been described in the literature 45 .

The development of the qualitative study as a preliminary stage for the epidemiological study contributed towards the work of constructing the object of study, such as determining the concept of trash. This permeated the entire process of drawing up research hypotheses and formulating the theoretical model; enabled a better theoretical basis for preparing the structured instruments, with greater emphasis on the environmental variables; and also furnished important elements for interpreting the investigation results.

Lastly, comparison between the epidemiological study (reflecting results at the macro level relating to the epidemiological impact of installing the sewage system within the Bahia Azul Program) and the anthropological study (reflecting results at the micro level, represented by the Nova Constituinte district) revealed differences in the perception of social inequalities. While the epidemiological study showed health benefits $25,26,27$, the anthropological study indicated a diversity of perception of these benefits among the residents 41 . Both disciplines captured different dimensions of the problem. If on the one hand, epidemiology provided a more wide-ranging and panoramic view of the phenomenon, on the other hand anthropology revealed internal factors at a more micro level that were thus more difficult to pick up using the epidemiological method. For this reason, the interdisciplinary approach used in this research contributed towards advancing the knowledge and constituted an epistemological exercise of synthesis.

This experience involved theoretical and methodological contributions that may add towards advancing other studies that support the use of approaches with multiple methods (triangulation) 46, as a means of empirical approximation towards comprehending complex issues. 


\section{Resumen}

En este artículo se discute el papel de los enfoques cualitativos en los estudios epidemiológicos, comenzando con una discusión general de ambos métodos. Se centra en un estudio de caso sobre el impacto en la salud de una intervención ambiental en Salvador, Bahía, Brasil. La mayoría de los estudios en esta línea, que se deriven de la fuente principal de la investigación, aporta poca discusión sobre los aspectos metodológicos y teóricos que participan en estudios a largo plazo. Cuatro aspectos específicos de esta experiencia son especialmente prominentes: (a) elaboración de cuestionarios para el estudio epidemiológico; (b) la construcción de un instrumento para medir los hábitos de higiene de observación; (c) un estudio etnográfico que precedió a la investigación epidemiológica; (d) observación de los efectos de las intervenciones sanitarias sobre las desigualdades en salud. Por último, el estudio considera en detalle cómo los resultados de los estudios cualitativos y cuantitativos se pueden sintetizar. Proporciona una visión general y crítica de estrategias de seguimiento, ilustraciones siempre que sea posible, con ejemplos apropiados.

Antropología Médica; Saneamiento; Impactos en la Salud

\section{Contributors}

C. Larrea-Killinger was involved in the study design, data collection, data interpretation and analysis, and writing the report. R. F. Rego, A. Strina, and M. L. Barreto were involved in the study design, data collection, statistical analysis, data interpretation and analysis, and writing the report.

\section{Acknowledgments}

This study was supported by Pronex-Centres of Excellence Programme CNPq 661086/1998-4; Department of Infraestructure, State Government of Bahia; and a Visiting Professor Fellowship from CAPES to first author in 2010. We thank the fieldwork team and the families that participated in the study.

\section{References}

1. Béhague DP, Gonçalves H, Victora CG. Anthropology and epidemiology: learning epistemological lessons through a collaborative venture. Ciênc Saúde Coletiva 2008; 13:1701-10.

2. Porter JD. Epidemiological reflections of the contribution of anthropology to public health policy and practice. J Biosoc Sci 2006; 38:133-44.

3. Almeida Filho N. Complejidad y transdiciplinariedad en el campo de la salud colectiva: evaluación de conceptos y aplicaciones. Salud Colect 2006; 2:123-46.

4. Breihl J. La sociedad, el debate de la modernidad y la nueva epidemiología. Rev Bras Epidemiol 1998; 1:207-33.

5. Dunn F, Craig RJ. Introduction: medical anthropology and epidemiology. In: Craig RJ, Stall R, Gifford SM, editors. Anthropology and epidemiology. interdisciplinary approaches to the study of health and disease. Dordrecht: Reidel Publishing Company; 1986. p. 3-34.

6. Trostle JA, Sommerfeld J. Medical anthropology and epidemiology. Annu Rev Anthropol 1996; 25:253-74.
7. Menéndez E. Antropologia médica e epidemiologia: processo de convergência ou medicalização. In: Alves C, Rabelo M, organizadores. Antropologia da saúde: traçando identidade e explorando fronteiras. Rio de Janeiro: Relumé-Dumará; 1998. p. 71-94.

8. Coreil J. The evolution of anthropology in international health. In: Coreil J, Mull JD, editors. Anthropology and primary health care. Boulder: Westview Press; 1990. p. 3-27.

9. Inhorn MC. Medical anthropology and epidemiology: divergences or convergences. Soc Sci Med 1995; 40:285-90.

10. Sevalho G, Castiel LD. Epidemiologia e antropologia médica: a possível in(ter)disciplinaridade. In: Alves C, Rabelo MA, organizadores. Antropologia da saúde: traçando identidade e explorando fronteiras. Rio de Janeiro: Relumé-Dumará; 1998. p. 47-69.

11. Sadler M. ¿QQué es lo cultural en la epidemiología cultural? Revista de Estudios Interdisciplinarios ASOSYLFF 2006; 1:91-100. 
12. Geertz C. La interpretación de las culturas. México DF: Gedisa; 1987.

13. Panter-Brick C, Clarke SE, Lomas H, Pinder M, Lindsay SW. Culturally compelling strategies for behaviour change: a social ecology model and case study in malaria prevention. Soc Sci Med 2006; 62:2810-25.

14. Agar M. Recasting the "ethno" in "epidemiology". Med Anthropol 1996; 16:391-403.

15. Trostle JA. Epidemiology and culture. New York: Cambridge University Press; 2005.

16. Bibeau G. ¿Hay una enfermedad en las Américas? Otro camino de la antropología médica para nuestro tiempo. In: Pinzón C, Suárez R, Garay G, editores. Cultura y salud en la construcción de las Américas. Bogotá: ICAN Colcultura; 1993. p. 41-70.

17. Almeida Filho N. Hacia una etnoepidemiología (esbozo de un nuevo paradigma epidemiológico). Rev Esc Salud Pública 1992; 3:33-40.

18. Scheper-Hughes N. Three propositions for a critically applied medical anthropology. Soc Sci Med 1990; 30:189-97.

19. Frankenberg R. Gramsci, culture and medical anthropology, Kundry and Parsifal? or rat's tail to sea serpent. Med Anthropol Q 1988; 2:324-38.

20. Scrimshaw S, Hurtado E. Anthropological approaches for programmes improvement. Los Angeles: University of California; 1987.

21. Hersch P, Haro A. ¿Epidemiología sociocultural o antropología médica? Algunos debates para un debate interdisciplinar. In: VII Coloquio de REDAM: Etnografías y Técnicas Cualitativas en Investigación Sociosanitaria. Un Debate Pendiente. http://porta lescolson.com/boletines/218/epidemiologia\%20 sociocultural.pdf (accessed on 27/Nov/2012).

22. Fernandes RP. Uma leitura sobre a perspectiva etnoepidemiológica. Ciênc Saúde Coletiva 2003; 8:765-74.

23. Almeida Filho N, Fernandes R, Larrea-Killinger C, Silva LAV. Construindo a etnoepidemiologia. In: Almeida-Filho N, Barreto ML, organizadores. Epidemiologia \& saúde: fundamentos, métodos e aplicações. Rio de Janeiro: Editora Guanabara Koogan; 2011. p. 386-95.

24. DiGiacomo SM. Can there be a "cultural epidemiology”? Med Anthropol Q 1999; 13:436-57.

25. Barreto ML, Genser B, Strina A, Teixeira MG, Assis AM, Rego RF, et al. Effect of city-wide sanitation programme on reduction in rate of childhood diarrhoea in northeast Brazil: assessment by two cohort studies. Lancet 2007; 370:1622-8.

26. Mascarini-Serra LM, Telles CA, Prado MS, Mattos SA, Strina A, Alcantara-Neves NM, et al. Reductions in the prevalence and incidence of geohelminth infections following a city-wide sanitation program in a Brazilian Urban Centre. PLoS Negl Trop Dis 2010; 4:e588.

27. Barreto ML, Genser B, Strina A, Teixeira MG, Assis AM, Rego RF, et al. Impact of a citywide sanitation program in Northeast Brazil on intestinal parasites infection in young children. Environ Health Perspect 2010; 118:1637-42.
28. Teixeira MG, Barreto ML, Costa MCN, Strina A, Martins Jr. D, Prado M. Sentinel areas: a monitoring strategy in public health. Cad Saúde Pública 2002; 18:1189-95.

29. Rego RF, Barreto ML, Santos R, Oliveira NF, Oliveira S. Rubbish index and diarrhoea in Salvador, Brazil. Trans R Soc Trop Med Hyg 2007; 101:722-9.

30. Clemens JD, Stanton BF. An educational intervention for altering water-sanitation behaviors to reduce childhood diarrhea in urban Bangladesh. I. Application of the case-control method for development of an intervention. Am J Epidemiol 1987; 125:284-91.

31. Traore E, Cousens S, Curtis V, Mertens T, Tall F, Traore A, et al. Child defecation behaviour, stool disposal practices, and childhood diarrhoea in Burkina Faso: results from a case-control study. J Epidemiol Community Health 1994; 48:270-5.

32. Gorter AC, Sandiford P, Pauw J, Morales P, Perez $\mathrm{RM}$, Alberts H. Hygiene behaviour in rural Nicaragua in relation to diarrhoea. Int J Epidemiol 1998; 27:1090-100.

33. Stanton BF, Clemens JD, Aziz KM, Rahman M. Twenty-four-hour recall, knowledge-attitudepractice questionnaires, and direct observations of sanitary practices: a comparative study. Bull World Health Organ 1987; 65:217-22.

34. Curtis V, Cousens S, Mertens T, Traore E, Kanki B, Diallo I. Structured observations of hygiene behaviours in Burkina Faso: validity, variability, and utility. Bull World Health Organ 1993; 71:23-32.

35. Manun'Ebo M, Cousens S, Haggerty P, Kalengaie M, Ashworth A, Kirkwood B. Measuring hygiene practices: a comparison of questionnaires with direct observations in rural Zaire. Trop Med Int Health 1997; 2:1015-21.

36. Bentley ME, Boot MT, Gittelsohn J, Stallings RY. The structured observation technique for the study of health behaviour. In: Cairncross S, Kochar V, editors. Studying hygiene behaviour: methods, issues and experiences. London: Sage; 1994. p. 102-20.

37. Cousens S, Kanki B, Toure S, Diallo I, Curtis V. Reactivity and repeatability of hygiene behaviour: structured observations from Burkina Faso. Soc Sci Med 1996; 43:1299-308.

38. Rêgo RC, Barreto ML, Killinger CL. O que é lixo afinal? Como pensam mulheres residentes na periferia de um grande centro urbano. Cad Saúde Pública 2002; 18:1583-91.

39. Cairncross S, Blumenthal U, Kolsky P, Moraes L, Tayeh A. The public and domestic domains in the transmission of disease. Trop Med Int Health 1996; 1:27-34.

40. Moraes LR. Acondicionamento e coleta de resíduos sólidos domiciliares e impactos na saúde de crianças residentes em assentamentos periurbanos de Salvador, Bahia, Brasil. Cad Saúde Pública 2007; 23 Suppl 4:S643-9. 
41. Larrea-Killinger C, Barreto ML. Salud ambiental urbana. Aproximaciones antropológicas y epidemiológicas de una intervención en saneamiento ambiental en un contexto de grandes desigualdades sociales. In: Larrea-Killinger C, Martínez A, editores. Antropología médica y políticas transnacionales: tendencias globales y experiencias locales. Barcelona: Institut Català d'Antropologia; 2006. p. 71-99. (QuAderns 22. Sèrie Monogràfics).

42. Larrea-Killinger C. Antropología y epidemiología: investigación interdisciplinar sobre saneamiento urbano en el nordeste brasileño. In: Larrea-Killinger C, Estrada F, editores. Antropología en un mundo en transformación. Barcelona: Publicaciones del Departamento de Antropología; 2004. p. 93-117.

43. Cairncross S, Hunt C, Boisson S, Bostoen K, Curtis V, Fung IC, et al. Water, sanitation and hygiene for the prevention of diarrhoea. Int J Epidemiol 2010; 39 Suppl 1:i193-205.

44. Hammersley M. The relationship between qualitative and quantitative research: paradigm loyalty versus methodological eclecticism. In: Richardson JTE, editor. Handbook of qualitative research methods for psychology and the social sciences. Leicester: BPS Books; 1996. p. 159-74.
45. Dixon-Woods M, Shaw RL, Agarwal S, Smith JA. The problem of appraising qualitative research. Qual Saf Health Care 2004; 13:223-5.

46. Minayo MC, Assis SG, Souza ER. Avaliação por triangulação de métodos: abordagem de programas sociais. Rio de Janeiro: Editora Fiocruz; 2008.

47. Barreto ML, Santos LM, Assis AM, Araújo MP, Farenzena GG, Santos PA, et al. Effect of vitamin A supplementation on diarrhoea and acute lowerrespiratory-tract infections in young children in Brazil. Lancet 1994; 344:228-31.

48. Larrea-Killinger C. Anthropology of health and sanitation: the sociocultural conditions of environmental health in two slums of the city of Salvador-Bahia (Brazil). Antropologia Medica 2001; 11-12:331-52.

49. Strina A, Cairncross S, Barreto ML, Larrea C, Prado MS. Childhood diarrhea and observed hygiene behavior in Salvador, Brazil. Am J Epidemiol 2003; 157:1032-8.

Submitted on $01 /$ Aug/2012

Final version resubmitted on 23/Oct/2012

Approved on 31/Oct/2012 